\title{
Comparison family structure of opiate dependents that refer to clinic of Rafsanjan University and normal group Mohammad Nazer*
}

Address: Rafsanjan University, Iran Rafsanjan Moradi Hospital Psychiatry Ward, Iran

* Corresponding author

from International Society on Brain and Behaviour: 2nd International Congress on Brain and Behaviour Thessaloniki, Greece. 17-20 November 2005

Published: 28 February 2006

Annals of General Psychiatry 2006, 5(SuppI I):S235 doi:I0.I I86/I744-859X-5-SI-S235

\section{Background \\ Beside genetic. Biology, psychology and environment fac- tors, family is a important and affective factor to build and appearance of personality and behavior in human beings and cause beginning and severity of addiction, however we decided to survey of influence of family structure to appearance of drug dependency}

\section{Materials and methods}

this is a cross sectional retrospective analyze. The basic aim is comparison of family structure of opiate dependence and Normal Group. Sample of addicts were selected with systematic random samplings and normal group were selected with matching with six factors: age, sex, academic grade, marriage, employment and no psychological and physical disease. We used two instruments for gathering information. One of them is drug dependency clinic questionnaire for screening and family structure questionnaire with 19 items. We used SPSS vers. 11.5 for analyze.

\section{Results}

there was physical disease in parents of addicts Group (AG) more than normal group (NG). Fathers of (AG) used opiate more than (NG), but there was no difference between Mothers. There was physical aggression between parents of (AG) more than (NG). In (AG) at first father than mother is dominant person in house. But in (NG) responsibility usually was divided between parents. Method of child training is dictator and carelessness on the other hand most of parents of (NG) use of assertive methods negatives treat in father of addicts is more than NG. Economy class of family of addicts significantly is from low and modest class but NG is from good and excellent class. Physical child abuse in parents of addicts was more than NG, but about psychological abuse there was no difference

\section{Discussion}

However kinds of method of therapy for drug dependency didn't have good results. Now the best methods for decrease of addiction is first prevention and one of important methods is pay attention to family structure for example relationship between parents, child abuse, physical and psychological disease and personality disorder in parents. Methods of child training, economy class, and dominate person in family that can influence in beginning and severity of addiction.

\section{References}

I. Royse D: Homelessness and gender in out of treatment drug abusers. Am J of Drug Alcohol Abuse 2000, 26:283-296.

2. Taylor J: Antisocial behavior, substance use, and somatization in families of adolescent drug abusers and adolescent controls. Journal of Drug and Alcohol Abuse 1998, 24:635-646.

3. Jennison K, Johnson KA: Alcoholism as a risk factor for Dsm IV. Defined alcohol abuse and dependency in American woman. Am J of Drug Alcohol Abuse 200I, 27:Parental349-374.

4. Griffin M, et al.: Mixed psychosocial outcomes of sisters from families with alcoholic parents. Am J of Drug Alcohol Abuse 1998, 24:153-67. 